\title{
The influence of spatial contrast on the frequency-dependent nature of vibration sensitivity
}

\author{
H. MUIJSER \\ TNO Medical Biological Laboratory, Rijswijk, The Netherlands
}

\begin{abstract}
Several stimulus configurations have been described for measuring the threshold for vibration perception. One such configuration, used primarily for screening for peripheral nervous system function, for example, consists of a matrix of 24 rows and 6 columns of tiny pins vibrating at $230 \mathrm{~Hz}$, with the even rows of pins vibrating in opposite phase to the uneven rows. In order to determine which class of mechanoreceptors is being tested with such a stimulus, the frequency dependence of the threshold for vibration perception was measured with a similar stimulus configuration in a group of younger subjects and in a group of older subjects. Moreover, the stimulus configuration could be changed from opposite phase stimulation to equal phase stimulation, wherein all pins vibrated with equal phase. In the range above $160 \mathrm{~Hz}$, it appeared that in younger subjects the threshold of the Pacinian receptor system was evaluated with both modes of stimulation, although the sensitivity for opposite phase stimulation was reduced relative to the sensitivity for equal phase stimulation. In the older subjects, equal phase stimulation also appeared to evaluate the Pacinian receptor system. However, with the opposite phase stimulation, the nonPacinian receptors tended to be evaluated. Below $100 \mathrm{~Hz}$, sensitivity was greater for opposite phase than for equal phase stimulation in both groups. Moreover, with both modes of stimulation, a sensitivity maximum at $40 \mathrm{~Hz}$ could be obtained, which was tentatively ascribed to the rapidly adapting class of mechanoreceptors.
\end{abstract}

Long-term overexposure to industrial and commercial chemicals such as methyl mercury, acrylamide, and $n$ hexane is known to produce peripheral neuropathy (Spencer \& Schaumburg, 1980). Because of the widespread occupational exposure to these and other potentially neurotoxic compounds, efforts have been made in recent years to develop noninvasive test instruments that can be used for monitoring preclinical signs of peripheral nervous system dysfunction. Since decreased vibration sensitivity is a common finding in patients with diagnosed polyneuropathies, a number of investigators (e.g., Dyck, 1975; Maurissen \& Weiss, 1980) have advocated vibration threshold testing for the screening of exposed populations.

The question in the present study concerned the type of stimulus configuration that would be most appropriate for evaluating deficits in vibration sensitivity. For example, one device that has been recommended by a number of investigators (Arezzo \& Schaumburg, 1980; Arezzo, Schaumburg, \& Petersen, 1983; Bleecker, 1985, 1986; Bove, Litwak, Arezzo, \& Baker, 1986; Lipton et al., 1987; Moody, Arezzo, \& Otto, 1986) is the Optacon Tactile Tester (Telesensory Systems, Palo Alto, CA). This device employs a stimulus configuration consisting of a

Correspondence should be addressed to $H$. Muijser, Section Neurotoxicology, TNO Medical Biological Laboratory, P.O. Box 45, 2280 AA Rijswijk ZH, The Netherlands. matrix of 24 rows and 6 columns of tiny pins driven at a frequency of $230 \mathrm{~Hz}$, with the even rows of pins driven in opposite phase to the uneven rows. Although the choice of $230 \mathrm{~Hz}$ is obviously based on the fact that the Pacinian receptor system has a sensitivity maximum in this frequency range, the choice of employing opposite phase stimulation is less clear. One could predict, for example, that because of the wide receptive fields of the Pacinian receptors (Johansson, 1978), the effects of opposite phase stimulation might partially cancel, leading to a reduced frequency maximum. Moreover, stimulation with a matrix of tiny pins rather than the single contactor that is typically used in psychophysical studies of vibration sensitivity increases the uncertainty as to whether the Pacinian receptors are the only mechanoreceptors being stimulated (Muijser, Hooisma, Hoogendijk, \& Twisk, 1986). For example, the rapidly adapting (RA) receptors, which seem to play an important role in the non-Pacinian receptor system (Bolanowski, Gescheider, Verrillo, \& Checkosky, 1988; Verrillo, 1979), are particularly sensitive to edges and possess small receptive fields (Johansson, 1978; Johansson, Landström, \& Lindström, 1982). Such properties make them suitable candidates for contributing to the perception of the stimulus presented by the Optacon Tactile Tester. In order to help define the nature of opposite phase stimulation, a device was constructed in which rows of pins could be driven either with opposite phase or with equal phase, and the frequencyresponse characteristics of both types of stimulation were 
examined in normal adults over a wide range of frequencies. Consistent with our expectations, sensitivity to opposite phase stimulation was decreased in the range of the Pacinian maximum. Surprisingly, however, results also indicated that in the non-Pacinian range, the frequency response was not flat as had been expected, but tended to show a maximum sensitivity at $40 \mathrm{~Hz}$.

\section{METHOD}

Two groups of 6 volunteers from the laboratory participated as subjects. The younger group consisted of 3 male and 3 female subjects with a mean age of 27.5 years $(S D=5.9)$. The older group consisted of 4 male and 2 female subjects with a mean age of 57.7 years $(S D=4.2)$. Vibratory thresholds were measured in 12 separate sessions at $10,20,28,40,56,80,112,160,224,320$, 450 , and $640 \mathrm{~Hz}$. The order of the frequencies was balanced over subjects. For each subject, testing was performed at a fixed time of the day, generally on successive working days. At the beginning of each session, the right hand and lower arm were warmed in a bucket containing water at $40^{\circ}-41^{\circ} \mathrm{C}$ (for $3 \mathrm{~min}$ ) and then dried with a towel. Testing was carried out with the volar tip of the right middle finger. The stimulus consisted of 36 pins arranged in two matrices. Each pin had a diameter of $0.4 \mathrm{~mm}$ and protruded $0.2 \mathrm{~mm}$ through a $1.0-\mathrm{mm}$ hole in a brass base plate. The pins of one matrix were situated in a $6 \times 6$ square lattice with 2 -mm spacing. Each pin of the second matrix was situated in the middle of 4 pins of the first matrix, thus forming also a square $6 \times 6$ matrix displaced laterally $1 \mathrm{~mm}$ in both planar directions. For clarity, only 18 pins instead of 72 were drawn in the insert in Figure 1. The pins of Matrix 1 were driven by a bridge connecting two 4809 shakers (Brüel and Kjar) and passed through holes in the mount of the pins of Matrix 2 (Figure 1). The pins of Matrix 2 were driven by a third shaker, placed between the other two. The lower resonance frequency of the bridge, constructed from an aluminum rectangular profile, was $1100 \mathrm{~Hz}$, well above the highest frequency used. This arrangement enabled stimulation with two matrices of pins that could vibrate either with the same or with the opposite phase. To counteract cooling of the skin during the experiment, the brass base plate mentioned above was warmed to $37^{\circ} \mathrm{C}$ and a $150-\mathrm{W}$ infrared lamp was placed at $60 \mathrm{~cm}$ above the hand and lower arm. Skin temperatures were not recorded. However, in comparable experiments (Muijser, Kruysbergen, Weert, \& Lamoré, 1990), mean skin temperature either showed no change (from $32.7^{\circ}$ to $33.3^{\circ} \mathrm{C}$, n.s.) or decreased slightly (from $35.3^{\circ}$ to $34.4^{\circ} \mathrm{C}$ ) during the experimental session. These changes are quite small, compared with the reported temperature effects on vibration sensitivity (Bolanowski \& Verrillo, 1982; Verrillo \& Bolanowski, 1986). To stabilize finger pressure, a horizontal lever with a $40-\mathrm{g}$ weight rested on the nail of the finger, and subjects were instructed to relax the arm and hand. The subjects were provided with a control box with four red lights and four push buttons. In each trial, the subjects had to decide during which one out of four periods, indicated by the lights, the stimulus was presented (forced choice with four alternatives). The duration of each period was $1.5 \mathrm{sec}$, and if a stimulus was present, it had a rise and fall time of $100 \mathrm{msec}$ and a duration of $600 \mathrm{msec}$. A BASIC program running on an HP-85 computer controlled stimulus presentation and recorded the responses. Stimuli were calibrated with an accelerometer (Brüel and Kjær, Type 4375). To balance measurements of the sensitivity for equal phase and opposite phase vibration of the pins during the sessions, trials for equal phase (A) and for opposite phase (B) vibrations were presented according to an $A B B A B A A B$ scheme. Both series consisted of 32 trials, and they were run independently of each other. Stimulus strength in a particular series was increased by $1.5 \mathrm{~dB}$ for the next trial after an incorrect answer in the previous trial of that series and decreased

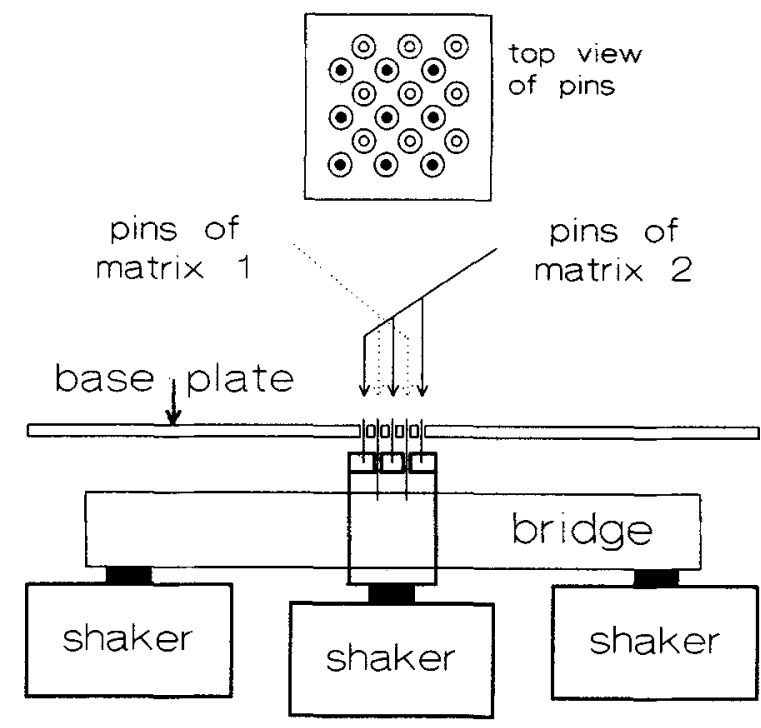

Figure 1. Schematic drawing of the stimulus arrangement. The longer pins (Matrix 1) are driven by the hridge connecting the two outer shakers. The shorter pins (Matrix 2) are driven by the shaker in the middle through a rectangular profile around the bridge. The pins of Matrix 1 pass through holes in the mount of the pins of Matrix 2. Both sets of pins protrude through holes in the brass base plate. Insert: Top view of the arrangement of the matrices of pins. For clarity, two matrices of 9 pins each are shown, rather than the $2 \cdot 36$ really present. The pins have a diameter of $0.4 \mathrm{~mm}$ and protrude $0.2 \mathrm{~mm}$ through a $1.0-\mathrm{mm}$ hole in the base plate. The holes are represented by the larger open circles. The pins of Matrices 1 and 2 have been drawn as open and filled circles, respectively. The center-to-center distance of the pins belonging to the same matrix is $2.0 \mathrm{~mm}$.

by $1.5 \mathrm{~dB}$ after three, not necessarily consecutive, correct answers in that series. In both series, the stimulus strength thus converged independently to the $75 \%$ correct level, because on the average there have to be three correct answers and one incorrect answer to ensure a stable baseline. To speed up convergence, stimulus strength was initially decreased by $6 \mathrm{~dB}$ after each response until the first incorrect response was made. Sensitivity was estimated from the mean value of the stimulus strength in Trials 20-31 in each series. Results were analyzed with appropriate analysis of variance programs from the BMDP statistical package (Dixon, 1988).

\section{RESULTS}

The sensitivities for equal phase vibrations and for opposite phase vibrations for the younger and older groups are presented in Figure 2. Data points at $640 \mathrm{~Hz}$ for the older group could not be ascertained, because 3 subjects could not perceive maximum stimulus strength at that frequency $(1.4 \mu \mathrm{m} \mathrm{rms})$. Curves were fitted to the data points with cubic splines (Slide Write plus package). The data were subjected to an analysis of variance with one between factor (age) and two within factors (frequency and phase). Results indicated that overall sensitivity was less in the older group than in the younger group $(p=.0013)$. In addition, frequency and phase had a significant effect on sensitivity ( $p=.0002$ and $p=.0005$, respectively), 
- equal phase stimulation

- opposite phase stimulation
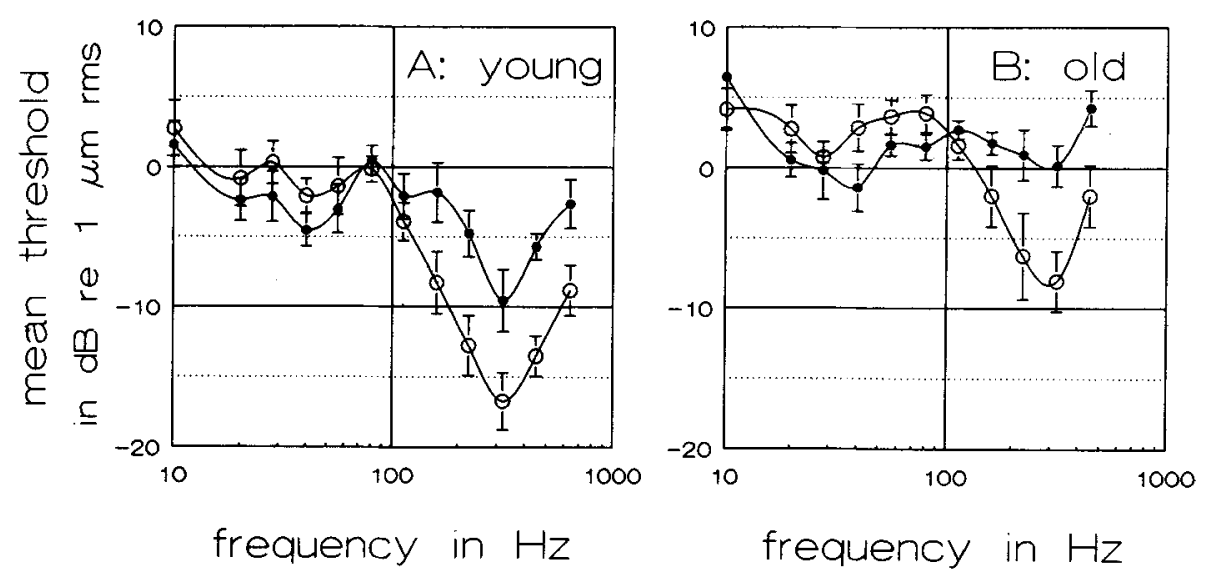

Figure 2. Frequency dependence of thresholds of perception for vibration of two matrices vibrating with equal phases (o) or with opposite phases $(\cdot)$. (A) Mean thresholds for 6 subjects with mean age 27.5 years $(S D=5.9)$. (B) Mean thresholds for 6 subjects with a mean age of 57.7 years $(S D=4.2)$.

and the interaction of frequency and phase was significant $(p<.0001)$.

Inspection of the curves revealed the source of the interaction. Above $100 \mathrm{~Hz}$, the threshold was higher for opposite phase vibrations of the two arrays of pins than it was for equal phase vibrations, whereas the opposite was found below $100 \mathrm{~Hz}$. Therefore, the data collected at $10,20,28,40,56$, and $80 \mathrm{~Hz}$ and the data collected at $112,160,224,320$, and $450 \mathrm{~Hz}$ were analyzed separately. The Pacinian sensitivity maximum at $300 \mathrm{~Hz}$ was clearly present in the curves of the equal phase vibration sensitivity of both the younger and the older groups. For opposite phase sensitivity, similar effects were also seen in the younger group, but less so in the older group. Analysis of variance revealed that above $100 \mathrm{~Hz}$ the sensitivity was quadratically related $(p=.0008)$ to the logarithm of the frequency with a maximum at $300 \mathrm{~Hz}$. In addition, the sensitivity in the Pacinian branch for equal phase vibrations was greater than the sensitivity for opposite phase vibrations for both groups $(p<.0001)$, with the younger group being more sensitive than the older group $(p=.0037)$.

Below $100 \mathrm{~Hz}$ (in the non-Pacinian part of the curve), sensitivity was greater for opposite phase vibrations than for equal phase vibrations $(p=.005)$. In addition, an effect of frequency was also seen $(p=.0004)$, but age was not significant $(p=.097)$. In order to investigate the nature of the effect of frequency below $100 \mathrm{~Hz}$ and to determine whether a sensitivity maximum at around $40 \mathrm{~Hz}$ was present, a trend analysis was carried out. The results revealed a quadratic trend in the data from $10-80 \mathrm{~Hz}(p=$ .0001 ). In addition, separate analyses showed that such a quadratic trend was not confined to opposite phase vibra- tions ( $p=.0002)$, but was also present for equal phase vibrations $(p=.0014)$.

\section{DISCUSSION}

It has been demonstrated in psychophysical experiments that vibratory sensations are mediated by at least two systems: the Pacinian receptor system and the non-Pacinian receptor system (see, e.g., Verrillo, 1963, 1966, 1968, 1985). The Pacinian system has a sensitivity maximum in the range $150-400 \mathrm{~Hz}$, depending on temperature, and it shows both spatial and temporal integration. In contrast, the frequency sensitivity of the non-Pacinian receptor system is virtually flat (Verrillo \& Bolanowski, 1986), with neither spatial nor temporal integration present.

In contrast to the psychophysical data, four types of low threshold mechanoreceptors have been identified in electrophysiological experiments: the Pacinian receptor, the RA receptor, and two slowly adapting receptors, SAI and SAII (see, e.g., Vallbo \& Johansson, 1984). A number of investigators (Bolanowski et al., 1988; Capraro, Verrillo, \& Zwislocki, 1979; Lamoré \& Keemink, 1988; Verrillo \& Bolanowski, 1986) have proposed identifications of the electrophysiologically defined receptor types with different parts of the psychophysically measured sensitivity curve as a function of frequency. While the identification of Pacinian receptors with a sensitivity maximum around $250 \mathrm{~Hz}$ has been generally accepted, evidence for the identification of the other three is less clear-cut. RA receptors, however, do seem to play a major role in the non-Pacinian part of the curve. A tuning curve however, with maximum sensitivity at around $40 \mathrm{~Hz}$ could be measured electrophysiologically in RA recep- 
tors of monkeys (see, e.g., Freeman \& Johnson, 1982; Mountcastle, Talbot, Sakata, \& Hyvärinen, 1969; Talbot, Darian-Smith, Kornhuber, \& Mountcastle, 1968), but a tuning curve at around $40 \mathrm{~Hz}$ has not unambiguously been demonstrated psychophysically.

The Pacinian maximum found in the present experiment was in the range of $300-350 \mathrm{~Hz}$, which is similar to the values given by Bolanowski and Verrillo (1982) for a skin temperature of $35^{\circ} \mathrm{C}$. At the Pacinian maximum, sensitivity was lower for opposite phase vibrations of the pins than for equal phase vibrations, for both age groups. This finding supports the hypothesis that the vibrations with opposite phases of the two sets of pins tend to cancel out in the wide receptive fields of the Pacinian receptors. However, the expected more or less flat frequency dependence of the sensitivity for opposite phase vibrations above $100 \mathrm{~Hz}$, indicating non-Pacinian determined thresholds, could be obtained in the older group only. In the younger group, the Pacinian curve was simply shifted upward. Hence, cancellation was limited to $8 \mathrm{~dB}$, indicating that at $320 \mathrm{~Hz}$ the amplitude of opposite phase vibrations would have to be 2.5 times larger than the amplitude of equal phase vibrations to reach threshold. It thus seems that in screening populations at risk for peripheral nervous system dysfunction, age and possibly the amount of sensory loss will determine which receptor system (Pacinian or non-Pacinian) is to be evaluated by measuring threshold sensitivity with opposite phase stimulation.

Johansson (1978) suggested a range of 3-5 mm for the diameter of the receptive fields of RA mechanoreceptors. The number of pins stimulating one RA receptor thus ranges from about 5-9 (cf. Figure 1, insert). Since this is clearly more than one, opposite phase stimulation results in larger spatial contrast than does equal phase stimulation. The higher sensitivity below $100 \mathrm{~Hz}$ for opposite phase vibrations as opposed to equal phase vibrations could thus result from the larger spatial contrast present in the former (Johansson et al., 1982). The shape, however, of the curves does not seem to depend on the relative phase of the vibrations of the two arrays of pins; both modes show a sensitivity maximum at $40 \mathrm{~Hz}$. It is tempting to identify the $40-\mathrm{Hz}$ sensitivity maximum with the sensitivity maxima at $40 \mathrm{~Hz}$ that have been found with electrophysiological techniques in RA receptors of monkeys. However, such an identification has to be established more firmly. For example, it might be that a more regular sensitivity maximum around $40 \mathrm{~Hz}$ can be obtained by balancing over frequencies in one session rather than over phase as has been done in the present experiments.

From the curves given by Verrillo and Bolanowski (1986) for the sensitivity of the non-Pacinian receptor system at the thenar eminence, using a $0.8 \mathrm{~mm}^{2}$ contactor, a sensitivity of $+15 \mathrm{~dB}$ to $+20 \mathrm{~dB}$ re $1 \mu \mathrm{m}$ rms can be read. From the curve given by Lamoré and Keemink (1988), using a $1 \mathrm{~mm}^{2}$ contactor, a sensitivity of $+10 \mathrm{~dB}$ re $1 \mu \mathrm{m} \mathrm{rms}$ at the first phalanx of the middle finger can be extracted. In the present study, the threshold at around $40 \mathrm{~Hz}$ was, especially for opposite phase vibrations, below $1 \mu \mathrm{m} \mathrm{rms}$. The low thresholds at $40 \mathrm{~Hz}$ to an array of vibrating pins as opposed to the much higher thresholds associated with studies in which single pins have been used suggest that a form of spatial integration may be present, a finding contrary to the accepted view that neither spatial nor temporal integration is present in the non-Pacinian system.

In conclusion, because of the uncertainties regarding the receptor systems involved, the stimulus configuration investigated seems less suitable for the assessment of sensory function at around $200 \mathrm{~Hz}$. Such a stimulus configuration seems optimal, however, for study of the nonPacinian receptor system at lower frequencies, due to the possibility of suppressing the sensitivity of the Pacinian receptor system.

\section{REFERENCES}

Arezzo, J. C., Schaumburg, H. H. (1980). The use of the Optacon as a screening device. Journal of Occupational Medicine, 22, $461-464$.

Arezzo, J. C., Schaumburg, H. H., \& Petersen, C. A. (1983). Rapid screening for peripheral neuropathy: A field study with the Optacon. Neurology, 33, 626-629.

BleECKER, M. L. (1985). Quantifying sensory loss in peripheral neuropathies. Neurobehavioral Toxicology \& Teratology, 7, 305-308.

BLEECKER, M. L. (1986). Vibration perception thresholds in entrapment and toxic neuropathies. Journal of Occupational Medicine, 28, 991-994.

Bolanowski, S. J., JR., Gescheider, G. A., Verrillo, R. T., \& Checkosky, C. M. (1988). Four channels mediate the mechanical aspects of touch. Journal of the Acoustical Society of America, 84, 1680-1694.

BolanowSKI, S. J., JR., \& VERRILLO, R. T. (1982). Temperature and criterion effects in a somatosensory subsystem: A neurophysiological and psychophysical study. Joumal of Neurophysiology, 48, 836-855.

Bove, F., Litwak, M. S., Arezzo, J. C., Baker, E. L. (1986). Quantitative sensory testing in occupational medicine. Seminars in Occupational Medicine, 1, 185-189.

Capraro, A. J., Verrillo, R. T., Zwislocki, J. J. (1979). Psychophysical evidence for a triplex system of cutaneous mechanoreception. Sensory Processes, 3, 334-352.

Dixon, W. K. (ED.) (1988). BMDP statistical software. Berkeley: University of California Press.

DYcK, F. J. (1975). Quantitation of cutaneous sensation in man. In P. J. Dyck, P. K. Thomas, \& E. H. Lambert (Eds.), Peripheral neuropathy (pp. 465-479). Philadelphia: W. B. Saunders.

Freeman, A. W., \& Johnson, K. O. (1982). A model accounting for effects of vibratory amplitude on responses of cutaneous mechanoreceptors in macaque monkey. Joumal of Physiology, 323, 43-64.

Johansson, R. S. (1978). Tactile sensibility in the human hand: Receptive field characteristics of mechanoreceptive units in the glabrous skin area. Journal of Physiology, 281, 101-123.

Johansson, R. S., LANDSTröm, U., \& LindSTRöm, R. (1982). Sensitivity to edges of mechanoreceptive afferent units innervating the glabrous skin of the human hand. Brain Research, 244, 27-32.

LAMORÉ, P. J. J., \& KeEminK, C. J. (1988). Evidence for different types of mechanoreceptors from measurements of the psychophysical threshold for vibrations under different stimulation conditions. Journal of the Acoustical Society of America, 83, 2339-2351.

Lipton, R. B., Galer, B. S., Dutcher, J. P., Portenoy, R. K., 
Berger, A., Arezzo, J. C., Mizruchi, M., Wiernik, P. H., \& SCHAUMBURG, H. H. (1987). Quantitative sensory testing demonstrates that subclinical sensory neuropathy is prevalent in patients with cancer. Archives of Neurology, 44, 944-946.

Maurissen, J. P. J., WeISS, B. (1980). Vibration sensitivity as an index of somatosensory function. In P. S. Spencer \& H. H. Schaumburg (Eds.), Experimental and clinical neurotoxicology (pp. 767-774). Baltimore: Williams \& Wilkins.

Moody, L., Arezzo, J. C., \& Otro, D. (1986). Screening occupational populations for asymptomatic or early peripheral neuropathy. Journal of Occupational Medicine, 28, 975-986.

Mountcastle, V. B., Talbot, W. H., Sakata, H., \& Hyvärinen, J. (1969). Cortical neuronal mechanisms in flutter-vibration studied in unanesthetized monkeys: Neuronal periodicity and frequency discrimination. Joumal of Neurophysiology, 32, 452-484.

Muiser, H., Hoorsma, J., Hoogenduk, E. M. G., \& Twisk, D. A. M. (1986). Vibration sensitivity as a parameter for detecting peripheral neuropathy: I. Results in healthy workers. International Archives of Occupational \& Environmental Health, 58, 287-299.

Muijser, H., Kruysbergen, N. van, Weert, C. de, \&amore, P. J. J. (1990). On the importance of the number of alternatives and response rules in the adaptive forced choice technique to measure sensory thresholds: Results of experiments in vibration perception and color discrimination and results of simulations. Unpublished manuscript.

SPENCER, P. S., SChAUMBuRg, H. H. (1980). Experimental and clinical neurotoxicology. Baltimore: Williams \& Wilkins.
Talbot, W. H., Darian-Smith, I., Kornhuber, H. H., MountCASTLE, V. B. (1968). The sense of flutter-vibration: Comparison of the human capacity with response patterns of mechanoreceptive afferents from the monkey hand. Journal of Neurophysiology, 31, 301-334.

Vallbo, A. B., Johansson, R. S. (1984). Properties of cutaneous mechanoreceptors in the human hand related to touch sensation. $\mathrm{Hu}$ man Neurobiology, 3, 3-14.

VERRILLO, R. T. (1963). Effect of contactor area on the vibrotactile threshold. Joumal of the Acoustical Society of America, 35, 1962-1966.

Verrillo, R. T. (1966). Specificity of a cutaneous receptor. Perception \& Psychophysics, 1, 149-153.

VerRILLO, R. T. (1968). A duplex mechanism of mechanoreception. In D. R. Kenshalo (Ed.), The skin senses (pp. 139-159). Springfield, IL: Thomas.

VERRILLO, R. T. (1979). The effect of surface gradients on vibrotactile thresholds. Sensory Processes, 3, 27-36.

VERRLLo, R. T. (1985). Psychophysics of vibrotactile stimulation. Journal of the Acoustical Society of America, 77, 225-232.

VERRILlo, R. T., BolanowsKI, S. J. (1986). The effects of skin temperature on the psychophysical responses to vibration on glabrous and hairy skin. Jourmal of the Acoustical Society of America, 80, 528-532.

(Manuscript received October 23, 1989; revision accepted for publication June 5,1990 .) 